\title{
Switched reluctance motor drives - recent advances
}

\author{
M EHSANI \\ Texas A\& M University, Department of Electrical Engineering, College Station, \\ TX 77843, USA \\ e-mail: ehsani@ee.tamu.edu
}

\begin{abstract}
The objective of this paper is to review the state-of-the-art and recent developments in Switched Reluctance Motor (SRM) drives. The interest for improved performance and reliability has motivated many SRM advances in the recent years. Even after almost 30 years of research in SRM, which might appear to be the simplest of all machines, there remain critical issues to be explored to gain deeper insight into the SRM technology. The paper briefly discusses the historical background and the basic operating principles of the motor. The topics discussed include the current state of research in converter topologies, control algorithms, torque ripple, noise, and sensorless operation. Recent advances in the field of SRMs indicates that they will have an increasing influence in the area of variable speed drives in the coming decades.
\end{abstract}

Keywords. Switched reluctance motors; converter topologies; control algorithms.

\section{Introduction}

Switched Reluctance Motor drives (SRMs) are relatively new entrants in the rapidly developing variable speed drives market. They are inherently variable speed drives which have simple construction, wide speed ranges, good energy efficiencies, high torque to inertia ratios, and high torque to power density ratios. The simple structure of SRMs will likely make them less expensive than the equivalent variable speed drives in mass production. An SRM has the flexibility of operating as a four-quadrant drive with independent control of speed and torque over a wide speed range. Their wide torque and speed range eliminates the need for expensive and troublesome mechanical gears and transmissions. Figure 1 shows a selection of SRMs with power ranging from $100 \mathrm{~W}$ to $75 \mathrm{~kW}$ and speeds ranging of 250 to $30000 \mathrm{rpm}$ (Lawrenson 1992).

\subsection{Historical background}

SRM is the modern version of the 'electromagnetic engine' which dates back to the late 1830 's. The modern era of developmental SRM started in 1972 when it was patented by 


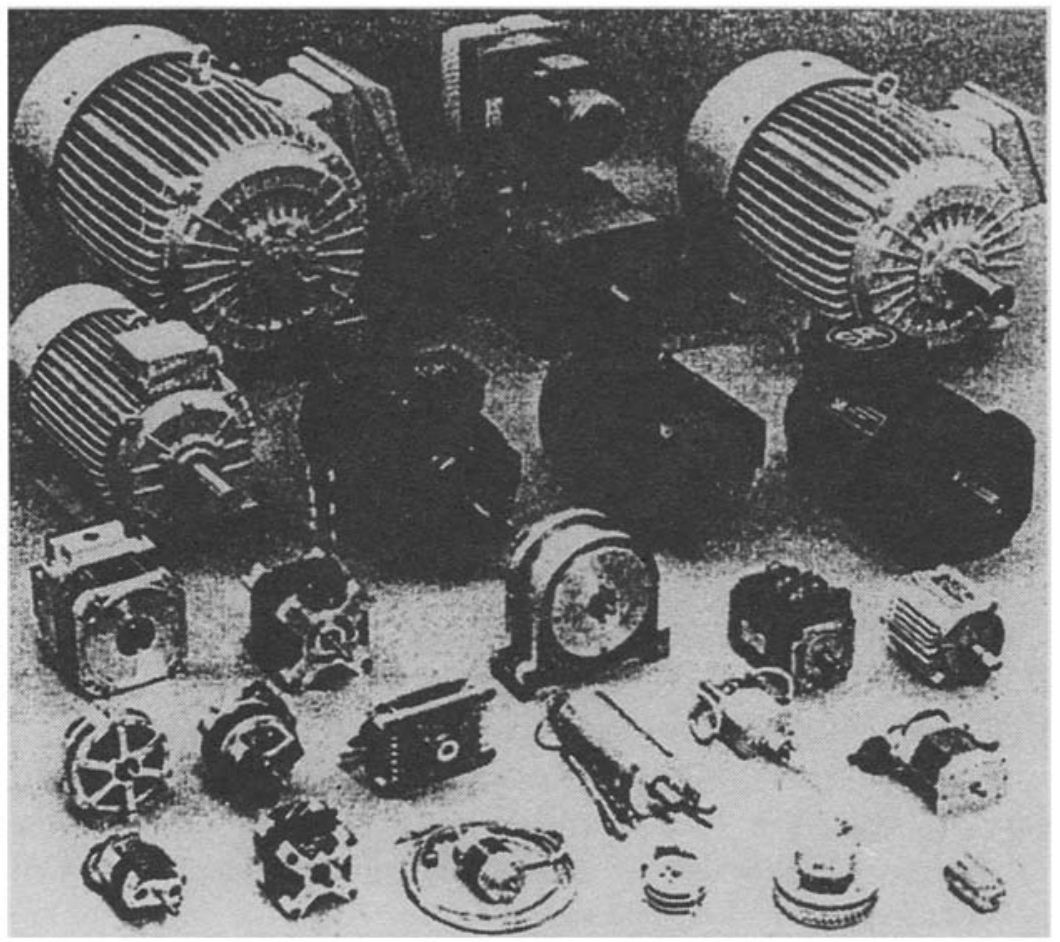

Figure 1. Assortment of SRMs.

Bedford. SRMs received considerable attention after the exemplary work done at the Universities of Leeds and Nottingham in the 1980s (Ray \& Davis 1979; Lawrenson et al 1980; Davis et al 1981). This spurred a series of research efforts all over the world, especially in Europe and in the US, resulting in several publications, patents and applications (Lawrenson 1992) which is illustrated in figure 2. Even after almost thirty years of research in SRM, which appears to be the simplest of all machines, there remain some critical issues which need further study.

\subsection{Basic principles of operation}

SRMs are structurally similar to Variable Reluctance Stepper motors, but they differ in the following aspects:

- stator phase currents are switched based on the rotor position feedback;

- the machine is designed to operate efficiently for a wide range of speed.

SRM has salient poles on both stator and rotor with concentrated windings only on the stator and no windings on the rotor. Windings on the diametrically opposite stator poles are connected in series. Figure 3 shows a typical 8/6 SRM. Currents in the stator windings are switched on and off in accordance with the rotor position feedback.

The basic principle of operation of SRM is like any other reluctance motor - torque is produced by the tendency of the rotor to align itself to the minimum reluctance position. As this is independent of the direction of the current in the stator windings, the power converter 


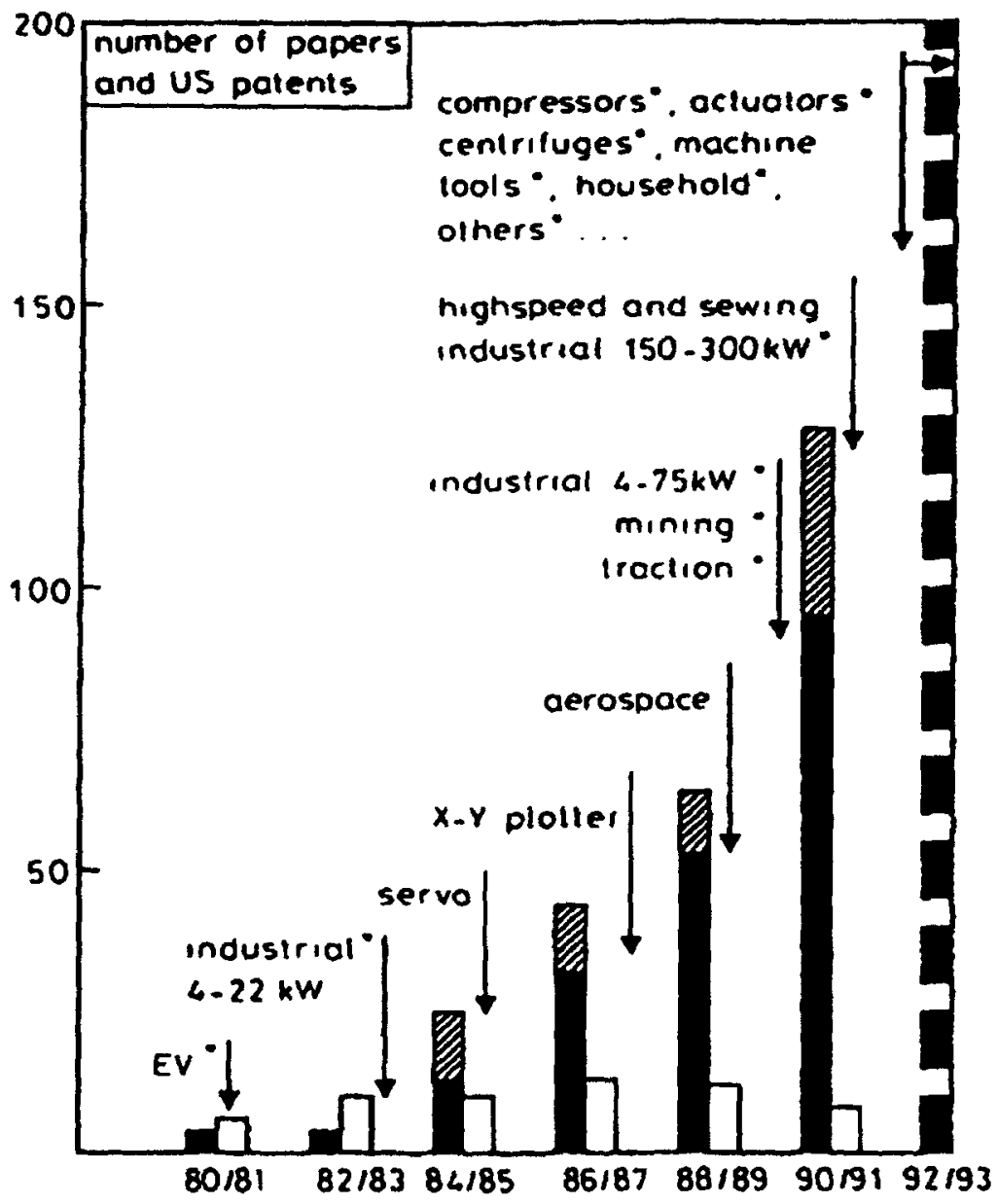

Figure 2. Approximate number of publications, patents and applications.

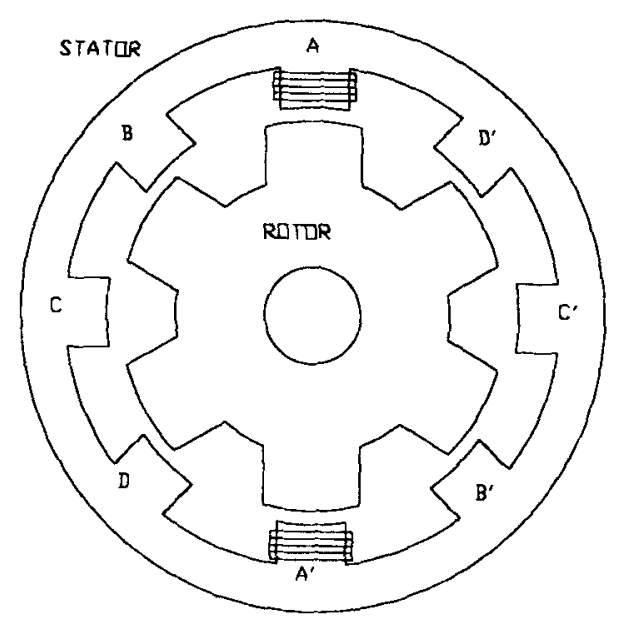

Figure 3. Typical 8/6 SRM. 


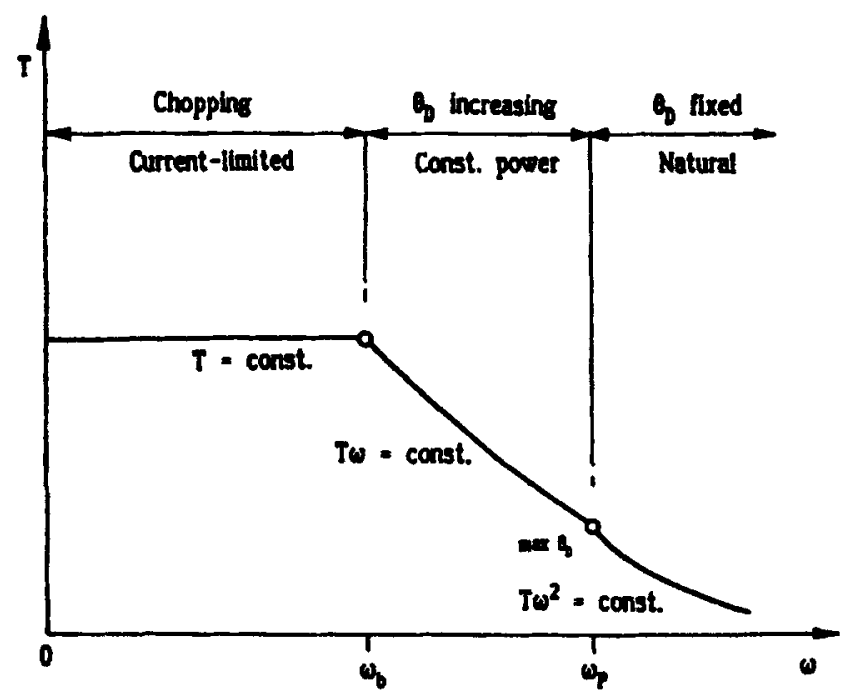

Figure 4. Torque-speed characteristics of an SRM.

circuit can be simplified. The radial magnetic attraction that operates the SRM is about ten times larger than the circumferential forces that operate an induction motor. The torquespeed characteristics of a SRM replicates a conventional DC machine characteristics under fixed firing switching strategy. Typical torque speed characteristics and variation in the flux linkage with current at different rotor positions are shown in figures 4 and 5 .

\section{Advances in converter design}

SRMs cannot operate directly with a $d c$ supply or the standard sinusoidal ac supply available 'off the wall'. Hence it is important that the design of the converter should be

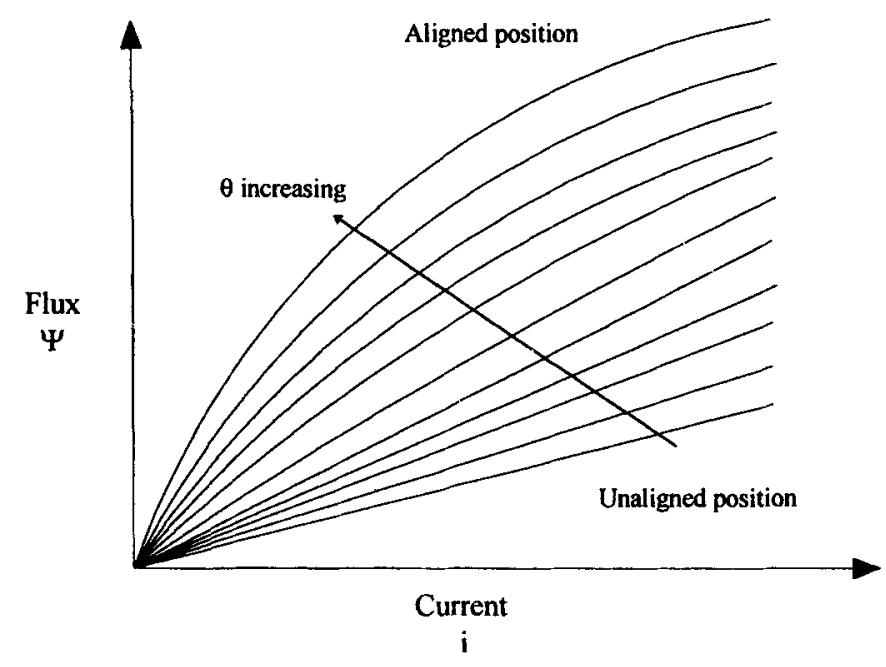

Figure 5. Flux/current/position curves. 
coordinated concurrently with the design of the motor to obtain an optimal design of the drive as a whole. Unlike the motors that operate with sinusoidal voltages and currents, the converter topology in an SRM is dependent on the machine design. The topology depends on the motor configuration, the number of stator and rotor poles and the associated conduction and overlap angle (Vukosavic \& Stefanovic 1991). In general, the starting torque requirements decides the current rating and the maximum speed of the motor decides the voltage rating of the inverter.

An ideal converter must satisfy

- low switches per phase ratio,

- ability to supply and control a commanded current independently and precisely,

- flexibility in adapting to any number of phases (odd or even),

- low VA rating for a given rating of the drive,

- robustness and reliability,

- good efficiency,

- ability to operate in all four quadrants effectively,

- less torque ripple and noise.

The most commonly used converter types are the classic half-bridge type converters and the split phase type converters. The classic type converter is the most flexible type converter but it requires a greater number of switches. The split phase type converter requires an even number of phases and has high active device rating, and hence is suitable only for low voltage and low power applications. Another type of converter suitable for star connected type SRM is the dual-decay type converter with flexibility of control in freewheeling mode and reduced device ratings (Ehsani et al 1993). Most of the converters developed recently are aimed at reducing the number of switches and are found to be more application-specific with some trade-offs. The different converter topologies are shown in figure 6.

\section{Advanced control schemes}

A reliable SRM drive system must have the following characteristics

- parameter insensitive control characteristics

- quick precise dynamic response with no overshoot

- rapid recovery from transient disturbances

Conventional linear controllers are quite sensitive to plant parameters. This along with the need for optimum performance of SRM like maximum efficiency, maximum torque and minimum torque ripple calls for sophisticated control strategy. The important control variables in an SRM, switch-on and switch-off angles, are a nonlinear complex function of many motor parameters and thereby require fine tuning (sophisticated control) for optimal performance. The advanced control strategies developed in the recent years include sliding mode control, Artificial Neural Networks and Fuzzy logic based control, self-tuning control etc. In a sliding mode control the states of the system are forced to slide on a given sliding 


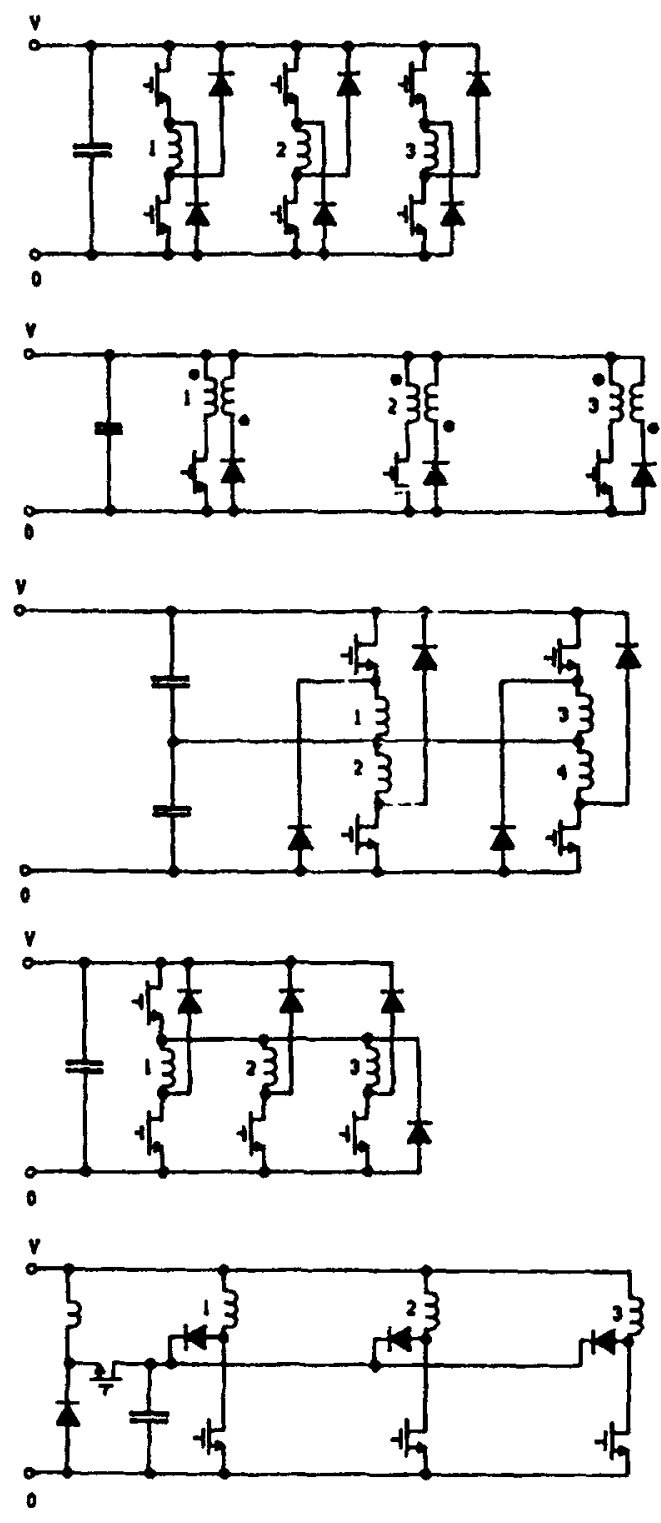

a)

b)

c)

d)

e)

Figure 6. SRM converter topologies. (a) Bridge, (b) bifilar, (c) split capacitor, (d) Miller, and (e) C-dump circuits.

surface in the state space. These methods are shown to provide a better torque ripple characteristics and are insensitive to parameter variations and disturbances. Artificial neural networks (ANNs) have been used successfully in the control of nonlinear dynamic systems (Reay et al 1993). The capability to accommodate accurate nonlinear modeling has made Artificial Neural Networks (ANNs) an ideal candidate to solve the control strategies of inherently nonlinear SRMs. Fuzzy logic controllers are gaining interest recently in the field of nonlinear control (Bolognani \& Zigliatto 1993). They offer the following advantages they do not require an accurate model of the plant, they can be designed on the basis of linguistic information obtained from the previous knowledge of the control of the machine and give better performance results than the conventional controllers. Amor et al (1992) 
suggested an adaptive control based on feedback linearization for less torque ripple (only position control) later used fifth order model (Amor et al 1993) to control speed and torque for adaptive control. A machine independent method control to minimize energy consumption is discussed by Kjaer et al (1994).

\subsection{Need for self-tuning control}

The following are the assumptions (Ehsani \& Ramani 1993) made in most of the conventional control methods:

- the inductance is symmetrical about the aligned position,

- all the rotor and stator poles have perfect symmetrical tooth structures,

- the inductance variation is time and temperature independent,

- saturation has no or very less effect on the inductance variation,

- the inductance profile is identical for all the phases,

- the inductance profile is identical for all the machines of the same rating in mass production.

In practice the above assumptions are not valid and these factors affect the sensitivity of a control algorithm. Control methods that can adapt to the parameter drifts are required to optimize the machine performance. Recently the problem of obtaining optimal performance from an SRM in the presence of parameter variation has gained considerable interest (Tandon et al 1996). New self-tuning algorithms which optimize the steady-state performance of the drive as measured by Torque per Ampere (TPA) have been introduced. It has been realized only recently that due to parameter variation and drift, the phase inductance profiles can significantly differ from the design data (Ehsani \& Ramani 1993; Ehsani et al 1993). Hence, it becomes necessary to use a controller with self-tuning capability if optimal performance of the SRM drive is to be maintained. Maximum TPA is desirable for any drive application because the motor may be described as a 'current to torque transducer'. Specifically, the following problems arise in practical SRMs.

- Due to manufacturing tolerances the inductance profile varies by as much as $10 \%$ from phase to phase of the motor and also from motor to motor with the same design and rating. It is noted that the minimum inductance does not show any significant variation. This is due to the very large air-gap at the unaligned position. However, the maximum inductance occurs at the aligned position where the air gap may be less than $1 \mathrm{~mm}$. Therefore any minor variations in the air-gap show up as change in the maximum inductance for each phase. Thus, the slope of the inductance profiles will also differ and the torque production is affected.

- With time, there will be wear on the bearings, as a result of which the air-gap may change or acquire a small eccentricity. Again, this has an impact on the maximum inductance of each phase. 


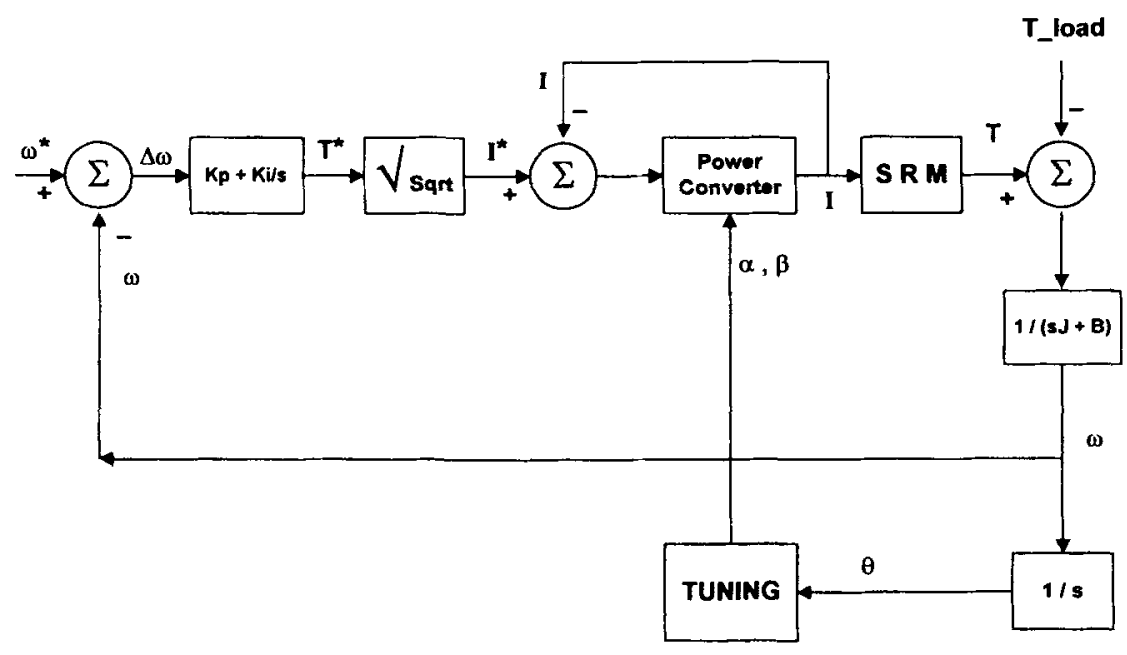

Figure 7. Control block diagram with self-tuning algorithm.

Hence, the optimal values of the turn-on angle calculated off-line are sufficient for the TPA maximization. An on-line, self-tuning algorithm to determine the optimal value of the turn-off angle in the presence of parameter variations which alter the inductance profiles has proven to produce superior steady state performance. Figure 7 shows the block diagram of the above mentioned self-tuning control. The inherent simplicity of this new approach makes it ideal for real-time implementation in a digital control system. The control scheme is applicable to any SRM drive operated with a shaft position sensor, and does not depend on the number of phases, poles or HP of the motor.

\section{Advances in sensorless operation}

Closed loop operation of an SRM requires rotor position information for satisfactory performance. Conventional methods used for position sensing include resolvers, inductive or Hall effect sensors and optical encoders. These have the disadvantages like additional cost, additional electrical connections, mechanical alignment problem, less suitability to space restricted application and the significant disadvantage of being a potential source of unreliability. These lead to the research in sensorless operation of SRMs, resulting in several techniques in the past two decades. Most of the existing methods extract the rotor position information from the measurable electrical parameters. These techniques eliminate the requirement of the conventional position sensors, thereby increasing the reliability of the motor drive system considerably. They can be classified as below.

(1) Active probing methods: These methods utilize the responses of diagnostic signals injected into the passive (un-energized) phase of an SRM. These methods are suitable for low speeds as the time window for passive phase measurement reduces at high speeds. Usually, the phase to be energized next is diagnosed for position estimation. They can be further classified as (a) Linear relation methods, and (b) inverse relation methods 
(a) Linear relation methods - In these methods, the signal containing position information is directly proportional to the phase inductance. In a typical method the rate of change of phase current, which is influenced by the incremental inductance, is monitored (Acarnley et al 1985). Rotor position can now be deduced as the incremental inductance is a function of rotor position. This has an advantage of deducing the rotor position even at zero speed. Another method which is robust to switching noise was presented by Ehsani and coworkers (Ehsani \& Ramani 1994; Ehsani et al 1994) and called the PM encoder technique. A sinusoidal carrier voltage signal of frequency much higher than that of the frequency of variation of inductance is chosen. Thus, the transient variation of the current phase will contain the information about the dynamic motor winding inductance. This encoded inductance information is decoded using zero crossing detectors for the voltage and current. The demodulator generates a square wave signal whose pulse width variation represents the phase inductance variation.

Also a modified PM encoder technique is presented which is suitable for a wide range of speeds. Mathematical analysis and simulation results show that PM technique is more sensitive for lower values of inductance and AM technique is more sensitive for higher inductance values. To achieve a better sensitivity, a level crossing detector is used instead of a zero crossing detector. The level crossing detector is set to a threshold value. Now the square wave output corresponds to the phase angle variation with respect to the threshold value other than zero which gives better sensitivity than the above PM method.

(b) Inverse relation methods - In these methods, the position information encoded signals are inversely proportional to the phase inductance. At high speeds, the motional EMF is very high, the current will never reach the rated value resulting in a 'single pulse' mode. In this mode, the current gradient in the next phase to be excited has the position information (Acarnley et al 1985). At the turn-on position, as the resistive voltage drop and the motional EMF are negligible, the initial rate of change of current is inversely proportional to the incremental inductance which gives the position information directly. The sensorless operation is implemented by comparing the initial current gradient with a optimal current gradient. In another method called the Amplitude Modulation (AM) method (Ehsani et al 1990; Ehsani 1991), the position information can be obtained from the amplitude of the current as it is directly proportional to the inductance variation. In this method, the envelope of the modulated current signal is detected. In addition, the information can be decoded by measuring the amplitude in terms of angles using a level crossing detector.

(2) Non-intrusive methods: In these methods, the rotor position is obtained based on the measurable parameters without using any diagnostic or probing signals. Neglecting $R$, at low speeds the incremental inductance $l=\mathrm{d} \psi / \mathrm{d} i$ is a function of $\theta$ for constant $i$. Therefore, ' $\mathrm{d} t$ ', rise time or fall time, can be used to obtain the position information. The flux linkage curve information on a multi-dimensional look-up table can be used to determine rotor position (Hedland 1986, 1992). In a more recent method called active phase vector method (Ehsani et al 1994), a composite vector which is directly proportional to the inductance is obtained based on the discrete form of voltage equation for different 
modes of operation. Active phase vector methods are computationally less intensive and digital implementation is easy.

(3) Open loop or synchronous control method: These methods are based on synchronous control and do not actually provide any position information. The motor is run from a variable frequency oscillator and change is made only to the dwell angle to improve the stability (Miller et al 1985).

(4) Other methods: Some other methods are as below.

(a) Observer based-Observer method reconstructs the state of the SRM drive system on the basis of known system inputs and system measurements (Lumsdaine \& Lang 1990). Measurements of input voltages and currents were utilized. An accurate mathematical model including mechanical load (in state space form) to estimate current, flux linkage, speed and rotor position which was compared with actual current and error adjustment made using an adjustment matrix to estimate the position is used.

(b) Mutually induced voltage based methods - In this method, the mutually induced voltage in an un-energized phase due to current in energized phase is monitored to obtain the position information (Hussain \& Ehsani 1994).

(c) Design based method - This method is based on altering slightly the structure of at least one of stator and/or rotor pole faces which will introduce a perturbation in the inductance profile of the motor while it is running (Bartos et al 1993). The perturbations can be produced by introducing a notch or bump in the stator and/or rotor pole faces. The frequency of these perturbations gives direct information on the speed of the motor.

The corruption of position information due to the secondary effects of the existing sensorless methods must be considered to improve accuracy. It is found that a trade-off exists between extensive computation and good resolution in sensorless position sensing. There is still much room for improvement as there are no accurate, commercially applicable methods available. The need for inexpensive, reliable, indirect position sensing technique for a wide range of speed, still exists. The advances made in the field of power electronics, motion control and signal processing can be used to improve the commercial applicability of the existing methods. The existing computationally intensive, high resolution sensorless techniques can be made commercially viable in the future with the advances made in the computational power of Digital Signal Processors. Further development resulting in commercially applicable, inexpensive techniques is expected. More research will be necessary for a method with good positional accuracy and suitable for commercial application.

\section{Overview of critical issues}

Apart from the numerous advantages, SRMs are also known for their high torque pulsations, high acoustic noise and reliability issues due to sensor based operation. 


\subsection{Torque ripple}

The nonlinear coupling between the rotor position, phase current and overlap angle and the doubly salient geometric structure of the SRM are the intrinsic causes of torque ripple in a SRM. Torque ripple is very undesirable in low speed and servo type applications. Several methods have been developed to reduce torque ripple based on machine design or control strategies.

5.1a Design based methods: Torque ripple can be minimized by suitably designing the magnetic structure of the machine (Tormey \& Torrey 1991). Comprehensive procedures, beginning with the fundamental selection of pole numbers and geometry, for designing SRM drives for low torque ripple applications has been presented in the literature (Wallace \& Taylor 1990). Values for specific torque are used to estimate the required SRM size and are obtained from empirical data or from an analytical estimation method. Pole numbers are chosen based on the speed and torque-ripple specifications for the design. The pole numbers define a range of feasible pole arc combinations. The centre pole arc values are chosen as a starting point. The current density in the phase winding is also chosen based on the thermal constraint of the application. The pole arcs and motor dimensions which yield minimum ripple are selected as the candidate design which is further evaluated using the dynamic SRM model.

5.1b Control based methods: Classical linear controllers cannot eliminate the torque pulsations. The fundamental approach is by optimal current profiling that reduces torque pulsations. Torque ripple can be reduced by using a current-tracking control method in which the desired stator currents are computed by linearizing and decoupling transformation. The shape of static torque-angle-current characteristics of SRM drive can be fully determined by a series of measurements performed with the drive in a self-learning mode (Kavanagh et al 1991). Based on this, the current required to obtain the optimum torque contribution from each phase, at each rotor position, can be determined for a smooth torque performance. A single input, linear, decoupled output torque controller based on optimal precalculation of the phase current profile provides low torque ripple (Schramm et al 1992). A bi-cubic spline interpolation was used to model the nonlinear experimental data. This method optimizes the current overlap at all torque levels so as to minimize the peak phase current. This current profiling algorithm results in the highest possible operating speed range under constant torque operation. The torque output is decoupled single-input linear function of torque input demand. Neural techniques can learn the current profiles required to minimize torque ripple and to satisfy other performance criteria on-line (Reay et al 1993). Torque measurement is required to train the neural network. PWM current control can be used for smooth operation of an SRM drive (Hussain \& Ehsani 1994). The torque pulsations during commutation are minimized by a current control strategy which allows simultaneous conduction of two positive torque producing phases over an extended predefined region. The effects of saturation can also be taken into account. 


\subsection{Acoustic noise}

Acoustic noise levels in SRMs are relatively high when compared to other ac drives. The acoustic noise has both magnetic and mechanical origin (Cameron 1992). The possible sources include radial attractive forces between the rotor and stator, stator vibrations induced by the torque ripple, stator winding vibrations induced by the interaction of the stator current and the local magnetic field, magnetostrictive forces in the stator laminations, unbalanced magnetic and mechanical forces on the rotor due to manufacturing asymmetry windage and bearing vibrations. Of these, the dominant one is shown to be the radial vibrations of the stator. Solving the noise problem can be approached either from the motor design point of view or the control point of view or a combination of these two. Acoustic noise can be reduced to any required level by current shaping or by introducing dither into the turn-on and turn-off angles. In another technique a chopper is introduced between rectifier and converter to reduce the phase voltage with respect to the speed (Pillay et al 1994). The voltage smoothing method reduces the rate of change of radial force and produces a smaller vibration (Pollock \& Wu 1995). A three-stage commutation technique has been described in the literature which cancels the stator vibrations when the power converter does not have a zero volt loop by employing the three stage commutation technique at the beginning and end of the zero volt loop. The active cancellation methods like the three stage commutation technique are superior to the voltage smoothing method since they allow the energy to be dissipated in subsequent vibrations which can completely oppose each other. Research in this area is still in its infancy and further developments are expected in the near future.

\section{Current state of research}

\subsection{SR generators}

Fukao (1986) discussed the principles and output characteristics of a super high speed reluctance generator system. Cameron et al (1992) discussed the computer-aided design of a VR generator and later about the control aspects of a high speed VR generator (Cameron \& Lang 1992) system. Radun (1994) discussed the analysis and design of an aircraft engine starter/generator. He proposed different excitation systems including one for three phase generation. Torrey \& Hassanin (1995) present the design methodology for low-speed VRGs for renewable energy systems.

\subsection{Fault tolerance}

SRMs inherently have a good fault tolerance capability in the sense that they can operate with faulted motor windings or inverter circuitry. The magnetic independence of the motor phases and the circuit independence of the SRM converter gives SRM that capability. Stephens (1991) discussed the different types of faults that can occur and suggested a method to sense and isolate the faulted winding. Miller (1995) analysed SRM under faulted condition using FEM, magnetic modeling, actual experiments as well as a simulation software. 


\subsection{Losses and temperature rise}

Core losses in SRM forms a significant part of the total losses. Materu \& Krishnan (1988) presented a method of calculating the iron losses based on the flux density waveform including saturation and presented a computationally intensive procedure using FEM timestepping. Metawally et al (1988) discussed the core loss in SRM based on experimental results. Faiz \& Dadgari (1991) analysed the heat distribution and thermal calculations for multitooth SRM under natural and forced cooling condition and compared it with experimental results. Corda \& Olaca (1993) predicted (analysed) losses in the converter of SR drive under different modes of operation. The prediction of converter losses, for a given converter topology and method of control, is useful when selecting the type of power semiconductor switching components and design parameters of control with respect to efficiency of the drive. The prediction of converter losses is also useful for the correct thermal design. A new approach to calculate core losses was developed by Hayashi \& Miller (1994) in matrix form using the Steinmetz equation.

\section{Applications}

SRMs have been successfully applied to a variety of applications resulting in high performance drives. Figure 8 shows typical efficiency vs. speed for curves for various $30 \mathrm{HP}$ motors. The first successful application was as general purpose industrial drives. More recently, they have been commercially applied to automotive utility motors. Good fault tolerance and ability to operate in harsh environments made SRMs successful candidates as coal-shearing machines, textile spinning drives, friction welding machines, food processor applications, plotters, aerospace and automotive applications. SRMs of $5 \mathrm{MW}$ at

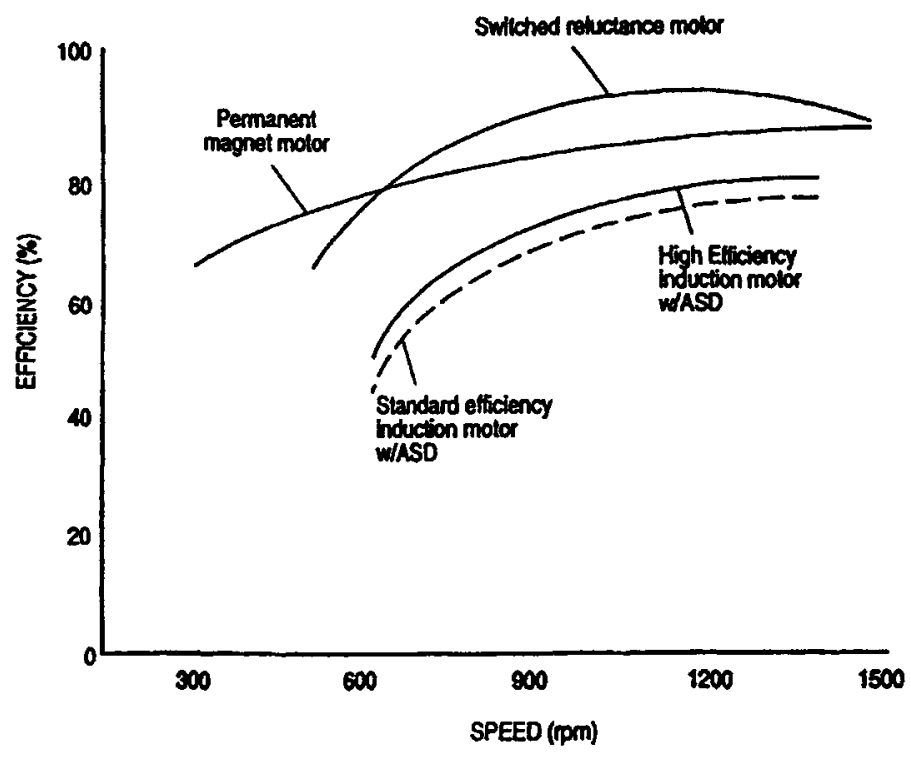

Figure 8. Efficiency vs. speed for various motors in the $30 \mathrm{HP}$ range. 
$50 \mathrm{rpm}$ to $10 \mathrm{~kW}$ at $100,000 \mathrm{rpm}$ have been built and tested successfully. Speed range of a SRM can be from $100: 1$ to $1000: 1$.

The fault-tolerance capability of SRMs is extremely good which makes it suitable for aerospace, automotive and industrial applications. The independence of each phase windings and the absence of shoot-through paths contributes to the fault tolerance of the SRMs. Typical applications include traction, domestic appliances, mining, servo type and batterypowered applications. The application areas of SRM are rapidly expanding as the SRMs can compete virtually in any industrial or domestic drive market.

\section{Conclusions}

The state-of-the-art SRM drive technology and the recent advances made in the research of SRM were discussed. A wide range of topics including converter topologies, control algorithms, sensorless operation, fault tolerance, noise and vibration issues were presented. From the above discussions it can be clearly seen that the SRM drive technology has come a long way. Further research is necessary in some critical areas for the SRM to be made commercially acceptable as a variable speed drive. Recent advances in power electronics and control systems are set to make SRM a commercially acceptable drive in the immediate future.

The author gratefully acknowledges the significant contribution of Mr. Anandan Velayutham Rajarathnam in this work.

\section{References}

Acarnley P P, Hill R J, Hooper C W 1985 Detection of rotor position in stepping and switched motors by monitoring of current waveforms. IEEE Trans. Ind. Electron. IE-32: 215-222

Amor L B, Dessaint L A, Akhrif O, Olivier G 1992 Adaptive feedback linearization for position control of a switched reluctance motor: Analysis and simulation. IEEE Ind. Electron. Conf. pp $150-159$

Amor L B, Dessaint L A, Akhrif O, Olivia G 1993 Adaptive input-output linearization of a switched reluctance motor for torque control. IEEE Ind. Electron. Conf., pp 2155-2160

Bartos, Houle T H, Johnson J H 1993 Switched reluctance motor with sensorless position detection. US Patent No. 5,256,923

Bolognani S, Zigliotto M 1993 Fuzzy logic control of a switched reluctance motor drive. IEEE Ind. Appl. Spec. Conf. Rec., pp 2049-2054

Cameron DE 1992 The origin and reduction of acoustic noise in doubly salient variable-reluctance motors. IEEE Trans. Ind. Appl. 28: 1250-1255

Cameron D E, Lang J H 1992 The control of high-speed variable-reluctance generators in electric power systems. IEEE Power Electron. Spec. Conf., pp 121-125

Cameron D E, Lang J H, Belanger D 1992 The computer-aided design of variable-reluctance generators. IEEE Appl. Power Electron. Conf., pp 114-120

Corda J, Olaca M 1993 Analysis of losses in power electronic converter of SR drive. Fifth Eur. Conf. on Power Electronics and Applications, pp 49-53 
Davis R M, Ray W F, Blake R J 1981 Inverter drive for switched reluctance: circuits and component ratings. Inst. Elec. Eng. Proc. B128: 126-136

Ehsani M 1991 Position sensor elimination technique for the switched reluctance motor drive. US Patent No. 5,072,166

Ehsani M, Ramani K R 1993 Direct control strategies based on sensing inductance in switched reluctance motors. IEEE Power Electron. Spec. Conf. Rec., pp 10-16

Ehsani M, Ramani K R 1994 New commutation methods in switched reluctance motors based on active phase vectors. IEEE Power Electron. Spec. Conf. Rec., pp 493-499

Ehsani M, Hussain I, Kulkarni A B 1990 Elimination of discrete position sensor and current sensor in switched reluctance motor drives. IEEE Ind. Appl. Spec. Conf. Proc. 518-524

Ehsani M, Husain I, Ramani K R, Galloway J H 1993 Dual-decay converter for switched reluctance motor drives in low-voltage applications. IEEE Trans. Power Electron. 8: 224-230

Ehsani M, Hussain I, Mahajan S, Ramani K R 1994 New modulation encoding techniques for indirect rotor position sensing in switched reluctance motors. IEEE Trans. Ind. Appl. 30: 85-91

Faiz J, Dadgari A 1991 Heat distribution and thermal calculation for switched reluctance motors. Fifth Int. Conf. Electrical Machines and Drives, Conf. Publ. No. 341, pp 305-310

Fukao T 1986 Principles and output characteristics of super high-speed reluctance generation system. IEEE Trans. Ind. Appl. 22: 702-707

Hayashi Y, Miller T J E 1994 A new approach to calculating core losses in the SRM. IEEE Ind. Appl. Spec. Conf. Rec., pp 322-328

Hedland M 1986 A method and a device for sensorless control of a reluctance motor. Int. Patent No. WO 91/02401

Hedland M 1992 Method and a device for sensorless control of a reluctance motor. US Patent No. $5,173,650$

Hussain I, Ehsani M 1994 Torque ripple minimization in switched reluctance motor drives by PWM current control. IEEE Appl. Power Electron. Conf., pp 72-77

Hussain I, Ehsani M 1994 Rotor position sensing in switched reluctance motor drives by measuring mutually induced voltages. IEEE Trans. Ind. Appl. 30: 665-672

Kavanagh R C, Murphy J M D, Egan M G 1991 Torque ripple minimization in switched reluctance drives using self-learning techniques. IEEE Ind. Electron. Conf., pp 289-294

Kjaer P C, Nielson P, Anderson L, Blaabjerg F 1994 A new energy optimizing control strategy for switched reluctance motors. IEEE Appl. Power Electron. Conf., pp 48-55

Lawrenson P J 1992 Switched reluctance drives: A perspective. Proc. Int. Conf. Elec. Machines 1: $12-21$

Lawrenson P J, Stephenson J M, Blenkinsop P T, Corda J, Fulton N N 1980 Variable-speed switched reluctance motors. Inst. Elec. Eng. Proc. B127: 253-265

Lumsdaine, Lang J H 1990 State observers for variable-reluctance motors. IEEE Trans. Ind. Electron. 37: 133-142

Materu P, Krishnan R 1988 Estimation of switched reluctance motor losses. IEEE Ind. Appl. Spec. Conf. Rec., pp 79-89

Metawally H M B, Faiz J, Finch J W 1988 Core loss in switched reluctance motor structure experimental results. Proc. Int. Conf. Electrical Machines, Pisa, Italy, 2: 31-34

Miller T J E 1993 Faults and unbalance forces in the switched reluctance machine. IEEE. Ind. Appl. Spec. Conf. Rec., pp 87-96

Miller T J E, Bass J T, Ehsani M 1985 Stabilization of variable-reluctance motor drives operating without shaft position sensor feedback. Incremental Motion Control Systems and Devices Proceedings, pp 361-368 
Pillay P, Samudio R, Ahmed M, Patel R 1994 A chopper-controlled SRM drive for reduced acoustic noise and improved ride-through capability using super capacitors. IEEE Ind. Appl. Spec. Conf. Rec., pp 313-321

Pollock C, Wu C Y 1995 Acoustic noise cancellation techniques for switched reluctance drives. IEEE Ind. Appl. Spec. Conf. Rec., pp 448-455

Radun A 1994 Generating with switched reluctance motor. IEEE Appl. Power Electron. Conf., pp $41-47$

Ray W F, Davis R M 1979 Inverter drive for doubly-salient reluctance motor: its fundamental behavior, linear analysis and cost implications. IEEE Elec. Power Appl. 2; 185-193

Reay D S, Green T C, Williams B W 1993 Neural networks used for torque ripple minimization from a switched reluctance motor. Fifth European Conf. on Power Electronics and Applications $1-6$

Schramm, Williams B W, Green T C 1992 Torque ripple reduction of switched reluctance motors by phase current optimal profiling. IEEE Power Electron. Spec. Conf. 856-860

Stephens C M 1991 Fault detection and management system for fault-tolerant switched reluctance motor drives. IEEE Trans. Ind. Appl. 27: 1098-1102

Tandon P, Rajarathnam A V, Ehsani M 1996 Self-tuning control of a switched reluctance motor drive with shaft position sensor. IEEE Ind. Appl. Spec. Conf. Rec. 101-108

Tormey D P, Torrey D A 1991 A comprehensive design procedure for low torque-ripple variable reluctance motor drives. IEEE 244-251

Torrey D A, Hassanin M 1995 The design of low-speed variable reluctance generators. IEEE Ind. Appl. Spec. Conf. Rec. 427-433

Vukosavic S, Stefanovic V R 1991 SRM inverter topologies: a comparative evaluation. IEEE Trans. Ind. Appl. 27: 1034-1047

Wallace R S, Taylor D G 1990 Three-phase switched reluctance motor design to reduce torque ripple. Proc. Int. Conf. Electrical Machines Cambridge, MA, pp 783-787 